\title{
REVIEWS
}

Reviews of books, reports, papers and other publications should be sent to $J$. Walter Giles, Book Review Co-ordinator, Lands Branch, Department of Lands and Forests, Parliament Buildings, Toronto 5, Ont. Please mention that you saw the review in The Forestry Chronicle when purchasing books from publishers.

\section{Statistical Techniques in Forestry}

By Andrew J. Nash, 1965. Lucas Bros. 146 pp.

Statistical Techniques in Forestry is a revised and extended version of Elementary Statistics for Foresters published in 1960.

Much of the material has been rearranged and new chapters have been added on regression and correlation and on experimental design and analysis of variance.

Standard statistical methods including graphical presentation and analysis, measures of central tendency and dispersion, and sampling techniques are clearly discussed and well illustrated with examples. Each chapter is well supplemented with numerous practice problems and exercises.

Dr. Nash has designed this book as a text in elementary statistics for forestry students. It should serve its purpose well. Practising foresters in need of some statistical review will find Statistical Techniques in Forestry a worthwhile addition to their library.

D. D. Munro

\section{Morphogenesis of Douglas Fir}

Abstract of U.B.C. Ph.D. Thesis by L. Heger, May, 1965

Widths of 22,734 bands of earlywood and latewood were measured systematically along the average radii at the centers of the annual height increments of 18 Douglas fir trees. Shapes of the annual growth layers of earlywood and of latewood, respectively, formed during an accrued growth period of 589 years were investigated:

(i) using relative measures embodied in diagrammatic computer outputs;

(ii) using absolute measures by statistical and graphical techniques;

(iii) by computing Hohenadl's form factor (lambda 0.9) for each year's growth of:

a) imaginary "earlywood stems" consisting of layers of earlywood;

b) imaginary "latewood stems" consisting of layers of latewood;

c) actual stems consisting of total annual layers.

The form of earlywood layers differed markedly and consistently from that of latewood layers. The maximum width of earlywood layers in individual trees occurred within a zone located in the upper portion of the live crown; in the stand it was within a zone parallel with the surface of crown canopy. Width of earlywood was at its minimun at some distance above the stem base. This distance increased with tree age. Latewood layers were usually widest along the basal portion of the stem. As a result, the form factors of "earlywood stems" were considerably higher than those of "latewood stems". 
The shapes of the growth layers, and hence the form of stems consisting of these layers, could not be reconciled satisfactorily with the tenets of Schwendener-Metzger's mechanistic, or Hartig's nutritional, or Jaccard's water conductive, or hormonal theories of stem formation. Therefore, a new scheme was proposed using the following concepts:

(1) Heating of stems by solar energy constitutes a purely physical process; the rate of energy transfer between a tree and its environment determines the temperature of its cambial tissues.

(2) Because trees are not homoiothermous organisms, at a given time various parts of the cambial cylinder may possess different temperatures even in an isothermal environment.

(3) A pronounced stratification of the environment due to gradients in air temperature or in length of time of positive net flux of energy has been observed in forests throughout the world.

(4) Radial growth may proceed at varying rates for unequal periods of time within the different parts of the cambial cylinder, depending largely on the levels of subcortical temperatures.

(5) Consequently, the shapes of the annual layers of earlywood and latewood may reflect the respective spring and summer environmental energy gradients.

(6) Then the average form of trees from forests of the temperate latitudes, which is that of a quadratic paraboloid, may reflect the average microclimatic structure prevailing in these forests during the growing season.

Form of open-grown trees, eccentricity of stems, roots and branches, and other so far unexplained anomalies in radial growth may be clarified similarly.

Indirect and some preliminary direct evidence supporting the proposed conceptual scheme of stem formation was presented. In addition, influence of some selected factors of macroclimate on the amount of radial growth expressed in terms of the average widths of growth layers was analysed. Individual trees have been used as sampling units. The trends in the growth series were removed by analysis of covariance: average layer width indices were derived by calculating deviations from the straight lines fitted by least squares to the adjusted mean layer widths. The degree of autocorrelation of both growth and weather series was largely nonsignificant. Correlations between the growth indices of earlywood and latewood were nonsignificant or low. In the individual trees, six weather variables accounted for from 10 to 48 per cent of the total variability observed in the radial growth of latewood. Temperatures of the previous summer could not be related to the amount of radial growth of earlywood of the current year. Since the approximate minimum true correlation in the universe was zero the general influence of macroclimate was nonsignificant.

It appears that other studies have neglected the influence on growth of microenvironmental factors and that there is need for research on the means by which distribution and amount of radial growth are controlled by the net flow of energy. 